\title{
Survival and prognostic factors in primary vaginal cancer: an analysis of 2004-2014 SEER data
}

\author{
Jianqin Huang ${ }^{1 *}$, Meiyu $\mathrm{Cai}^{2 *}$, Zhiling Zhu $^{1}$ \\ ${ }^{1}$ Department of Integrative Medicine, Obstetrics and Gynecology Hospital, Fudan University, Shanghai, China; ${ }^{2}$ Department of Quality \\ Management, Obstetrics and Gynecology Hospital, Fudan University, Shanghai, China \\ Contributions: (I) Conception and design: Z Zhu; (II) Administrative support: Z Zhu; (III) Provision of study materials or patients: J Huang, M Cai; (IV) \\ Collection and assembly of data: J Huang; (V) Data analysis and interpretation: J Huang, M Cai; (VI) Manuscript writing: All authors; (VII) Final \\ approval of manuscript: All authors. \\ "These authors contributed equally to this work. \\ Correspondence to: Zhiling Zhu, Department of Integrative Medicine, Obstetrics and Gynecology Hospital, Fudan University, 128 Shenyang Road, \\ Yangpu District, Shanghai 200090, China. Email: zhilingzhu888@126.com.
}

Background: Primary vaginal cancer (PVC) is a rare gynecological malignant tumor and we know little about its survival and prognostic factors. The purpose of this study is to evaluate the potential survival and prognostic factors in women with PVC.

Methods: We used data from the Surveillance, Epidemiology, and End Results (SEER) program to identify 1,781 women who had been diagnosed with PVC between 2004 and 2014. Univariate and multivariable analyses were used to evaluate cases survival and prognostic factors. A stratified analysis was further performed to analyze the prognostic factors in each stage.

Results: There were $20.0 \%$ of patients aged $\geq 80$ years and most women were married, $42.1 \%$, and then widowed, 25.2\%. The histology types include squamous (74.5\%), adenocarcinoma (16.7\%), melanoma (3.3\%) and sarcoma (1.5\%). Five-year cause-specific survival (CSS) rates were overall: $57.8 \%$, Stage I: 76.4\%, Stage II: $61.9 \%$, Stage III: $53.3 \%$ and Stage IV: $22.5 \%$. Univariate analysis showed that age, marital status, race, pathological grading, histology, TNM stage, tumor size, surgery and radiation were related to prognosis. The 5-year CSS of married women is $64.4 \%$, while those of divorced/separated and widowed are $56.6 \%$ and $44.1 \%$, respectively. Multivariate analysis indicated that age, histology, TNM stage, tumor size, surgery and radiation were independent prognostic factors. The elderly $(\geq 80)$ cases and those with melanoma were correlated to worse prognosis at any stage of PVC. As tumor stage progressed, both of the $\geq 80$ years old patients and the melanoma cases showed a decline tendency of mortality risk.

Conclusions: PVC is a rare gynecological malignant tumor and more likely to occur among older women. Squamous cell carcinoma is the most frequently observed histological type, while melanoma is extremely rare. Age, histology, TNM stage, tumor size, surgery and radiation are independent prognostic factors. Although marital status does not affect survival rates, married women are likely to live longer than widowed and divorced/separated cases. Age $\geq 80$ years seems to be an important cut point in the survival of vaginal cancer. Older age ( $\geq 80$ years) and melanoma have greater influences on mortality risk in early-stage disease.

Keywords: Survival; prognostic factors; primary vaginal cancer (PVC); Surveillance, Epidemiology, and End Results (SEER)

Submitted Apr 14, 2020. Accepted for publication Sep 14, 2020.

doi: $10.21037 /$ tcr-20-1825

View this article at: http://dx.doi.org/10.21037/tcr-20-1825 


\section{Introduction}

Primary vaginal cancer (PVC) is a rare malignancy, approximately accounting for $1 \%$ to $3 \%$ of all gynecologic malignancies (1). In the United States, only 4,620 new cases of vaginal cancer were expected to occur in 2016, while 950 patients were expected to die from it (2). And an estimated 4,810 new cases of PVC, and an estimated 1,240 PVC deaths, occurred in 2017 (3). Due to the rarity of this disease, there is still minimal information on its epidemiology, treatment, survival, and prognostic factors. PVC is predominantly a disease of older women and it is most frequently diagnosed in the sixth or seventh decade of life (4). The main pathological types of PVC are squamous cell carcinoma (SCC, 79-85\% of cases), adenocarcinoma (5-14\%) (5), melanoma (1-5\%) (6) and sarcoma. PVC is thought to share many of the same risk factors as cervical cancer, such as tobacco use, younger age at coitarche, human papillomavirus (HPV) infection, multiple sexual partners and long-term mucosal irritation or injury such as by prolonged pessary usage $(7,8)$. At present, no standardized treatment for this rare cancer is available. Surgery and radiation are the main treatments for vaginal cancer $(9,10)$. Previous studies have indicated that the dominant prognostic factors for PVC include age, histological type, grade of differentiation, stage, tumor size, tumor site, surgery, radiation and chemotherapy (5,11-15). Although some recent studies have shown marital status to be an independent predictor of survival in various gynecologic cancers, with married women enjoying longer survival and lower mortality than widows and single women (16-19), the effect of marital status on PVC prognosis had not, to our knowledge, been specially studied.

The SEER database currently includes patient data from 17 population-based cancer registries (26\% of the United States population). We therefore utilized this large population-based database to analyze survival and prognostic factors in PVC, and to evaluate clinical characteristics, including marital status, on mortality among women with PVC. Because staging likely affects relationships between clinical characteristics and mortality risk, we performed a stratified analysis to elucidate prognostic factors at each stage. We present the following article in accordance with the STROBE reporting checklist (available at http://dx.doi. org/10.21037/tcr-20-1825).

\section{Methods}

\section{Data extraction}

Women diagnosed with PVC between 2004 and 2014 were identified through the National Cancer Institute's SEER Program. The data had been authorized by SEER database and ethical review was not required. The study was conducted in accordance with the Declaration of Helsinki (as revised in 2013). We excluded patients who (I) were younger than 18 years at diagnosis; (II) had carcinoma in situ; (III) had another primary cancer at diagnosis, but the vaginal cancer was not the first one; or (IV) had no available data on TNM stage, survival, or marital status. The survival time was calculated on a monthly basis, starting from the diagnosis time of the patient, and ending on the day of death, loss to follow up or the follow-up deadline. The last follow-up date was December 31, 2014. The patients were followed up for 0-131 months, with a median follow-up time of 25 months. No patients were lost. A total of 1,781 eligible women with PVC were identified using SEER ${ }^{*}$ Stat 8.3.5.

\section{Statistical analysis}

The primary outcome of interest in this study was causespecific mortality. Clinical characteristics were summarized using frequency and percentage for categorical covariates. Categorical and continuous variables were compared using Fisher's exact test and Wilcoxon rank-sum test, respectively. Survival curves were generated using the Kaplan-Meier method. Statistical significance was assessed with the $\log$ rank $\chi^{2}$ test. The associations between vaginal cancer mortality risk within categories of year of diagnosis (5-year intervals: 2004-2008, 2009-2014), age at diagnosis (18-49, 50-69, 70-79, $\geq 80$ ), marital status (single, married, divorced/ separated, widowed), race (white, black, other, unknown), pathological grading (I, II, III, IV, Unknown), histotype (SCC, adenocarcinoma, melanoma, sarcoma, other), TNM stage (I, II, III, IV), tumor size $(<4 \mathrm{~cm}, \geq 4.0 \mathrm{~cm}$, unknown), surgery (yes, no, unknown), and radiation (yes, no) were estimated using Cox regression models. Multivariate adjusted hazard ratios (HR) and their associated $95 \%$ confidence intervals (CI) were calculated as estimates of relative mortality risk. As stage is a likely modifier of the relationships between clinical characteristics and mortality 
risk, we stratified our assessments of the effects of clinical characteristics by stage and $\mathrm{P}$ values for interactions that were calculated based on likelihood ratio testing. Analyses were performed using SAS version 9.4 (SAS Institute, INC, Cary, NC, USA), and figures were graphed using GraphPad Prism 8 (GraphPad Software, LLC, San Diego, USA). P values were two-sided. $\mathrm{P}<0.05$ was considered significant.

\section{Results}

Among the 1,781 patients, $14.6 \%$ were aged $18-49$ years at the time of diagnosis, and $20.0 \%$ aged $\geq 80$ years; $42.1 \%$ were married, and $25.2 \%$ were widowed; $78.4 \%$ were Caucasian and $14.9 \%$ were African-American. The histologies were $74.5 \%$ SCC, $16.7 \%$ adenocarcinoma, $3.3 \%$ melanoma and $1.5 \%$ sarcoma; disease stages were stage I: $32.8 \%$, stage II: $27.1 \%$, stage III: $20.0 \%$, and stage IV: $20.5 \%$. Among treatments, $35.6 \%$ of patients underwent surgery and $74.8 \%$ received radiation (Table 1 ).

Based on Kaplan-Meier curves by stage, 5-year CSS rates were entire cohort: $57.8 \%$, stage I: $76.4 \%$, stage II: 61.9\%, stage III: $53.3 \%$, and stage IV: $22.5 \%$ (Figure 1). Univariate cox analysis showed that age, marital status, race, pathological grading, histology, TNM stage, tumor size, surgery and radiation were related to prognosis (Figure 2). Five-year CSS gradually decreased as age increased (1849 years: $66.6 \%, 50-69$ years: $65.5 \%, 70-79$ years: $50.0 \%$, $\geq 80$ years: $38.5 \%$; $70-79$ vs. $18-49$ years: HR 1.73 , $\mathrm{P}=0.0001 ; \geq 80$ vs. $18-49$ years: HR $2.55, \mathrm{P}<0.0001)$. The 5 -year CSS of married women is $64.4 \%$, while those of divorced/separated and widowed are $56.6 \%$ and $44.1 \%$, respectively (divorced/separated vs. married: HR 1.27, $\mathrm{P}=0.0469$; widowed $v s$. married: HR $1.81, \mathrm{P}<0.0001)$. The 5 -year CSS of white is $58.6 \%$, while that of black is $51.7 \%$ (HR 1.25, $\mathrm{P}=0.0386$ ). Five-year CSS rates by pathological grade were grade I: $61.7 \%$, grade II: $61.0 \%$, grade III: $55.1 \%$, and grade IV: $36.2 \%$ (grade IV vs. grade I: HR 1.82 , $\mathrm{P}=0.0128)$. Women with SCC had the highest 5-year CSS rate $(63.6 \%)$, and those with melanoma had the lowest rate $(19.2 \%$; HR 2.70, $\mathrm{P}<0.0001)$. Five-year CSS was significantly better for women with tumors $<4 \mathrm{~cm}(71.8 \%)$ than for women with larger tumors (45.4\%; HR 2.49, $\mathrm{P}<0.0001)$; for patients who received no surgery (48.9\%) than those who underwent surgery $(72.1 \%$; HR 0.43 , $\mathrm{P}<0.0001)$; and for those who received no radiotherapy $(52.5 \%)$ than those who underwent radiotherapy $(59.4 \%$; HR 0.69, $\mathrm{P}<0.0001$; Table 2).
In multivariate analysis, age, histology, TNM stage, tumor size, surgery and radiation were independent prognostic factors. Women aged 18-49 years had lower mortality risks than women aged 70-79 years (HR: 1.48) and those aged $\geq 80$ years (HR: 2.62). Women with SCC had lower mortality risks than women diagnosed with sarcoma (HR: 1.98) or melanoma (HR: 4.35). Not surprisingly, stage was strongly related to risk, as women with stage I disease had lower mortality risks than those with stage II (HR: 1.77), stage III (HR: 2.28) or stage IV disease (HR: 5.43). Women with tumors larger than $4 \mathrm{~cm}$ had elevated risks of death (HR 1.62). Treatment with surgery and radiation reduced the mortality risk (HRs: 0.46 and 0.52 , respectively; Table 2).

We performed a stratified analysis to identify differences in prognostic factors in each stage (Table 3). Compared with women aged 18-49 years, those $\geq 80$ years had higher risk of death at each stage (stage I: HR 3.62, stage II: HR 2.7, stage III: HR 2.86, stage IV: HR 2.47, $\mathrm{P}<0.05)$. Women with melanoma also had higher mortality risk by disease stage compared with SCC [stage I: HR 14.41, stage III: HR 3.54, stage IV: HR 2.02, $\mathrm{P}<0.05$ (because only one melanoma patient had stage II disease, it was omitted from our analysis)]. As tumor stage progresses, its effects on mortality risk in patients aged $\geq 80$ years and those diagnosed with melanoma tends to decline.

\section{Discussion}

PVC is a rare gynecological malignancy. Only a few PVC retrospective studies have been published. However, clinical information including epidemiology, treatment, survival, and prognostic factors, is very limited.

Compared with cervical cancer, vaginal cancer is more likely to occur among older women (20). The median age for invasive cervical cancer was 47 years (21); whereas, the median age for invasive vaginal cancer was 68 years. And its incidence increases with age; about $50 \%$ of PVC diagnoses are reportedly made in patients aged $\geq 70$ years, and $20 \%$ in patients older than 80 years (5), which were similar to our findings of about $40 \%$ of PVC diagnosed in women aged $\geq 70$ years, and $20 \%$ in patients older than 80 years. SCC, the most common PVC histology, is reported to account for $79-85 \%$ of PVC and usually occurs in elderly women, followed by adenocarcinoma (5-14\%) (5), and melanoma $(1-5 \%)(6)$. The most common histology types in our study were SCC $(74.5 \%)$, adenocarcinoma $(16.7 \%)$, and melanoma $(3.3 \%)$, which were consistent with previous 
Table 1 Demographic and clinicopathological characteristics

\begin{tabular}{|c|c|c|}
\hline Variables & Number & $\%$ \\
\hline \multicolumn{3}{|l|}{ Diagnosis year } \\
\hline 2004-2008 & 803 & 45.1 \\
\hline 2009-2014 & 978 & 54.9 \\
\hline \multicolumn{3}{|l|}{ Age, years } \\
\hline $18-49$ & 260 & 14.6 \\
\hline $50-69$ & 818 & 45.9 \\
\hline $70-79$ & 347 & 19.5 \\
\hline$\geq 80$ & 356 & 20.0 \\
\hline \multicolumn{3}{|l|}{ Race } \\
\hline White & 1,397 & 78.4 \\
\hline Other & 114 & 6.4 \\
\hline Black & 265 & 14.9 \\
\hline Unknown & 5 & 0.3 \\
\hline \multicolumn{3}{|l|}{ Marital status } \\
\hline Married & 750 & 42.1 \\
\hline Separated/divorced & 276 & 15.5 \\
\hline Single & 307 & 17.2 \\
\hline Widowed & 448 & 25.2 \\
\hline \multicolumn{3}{|l|}{ Pathological grading } \\
\hline Grade I & 136 & 7.6 \\
\hline Grade II & 551 & 30.9 \\
\hline Grade III & 562 & 31.6 \\
\hline Grade IV & 50 & 2.8 \\
\hline Unknown & 482 & 27.1 \\
\hline \multicolumn{3}{|l|}{ Histology } \\
\hline Squamous cell carcinoma & 1,326 & 74.5 \\
\hline Adenocarcinoma & 298 & 16.7 \\
\hline Melanoma & 58 & 3.3 \\
\hline Sarcoma & 27 & 1.5 \\
\hline Other & 72 & 4.0 \\
\hline \multicolumn{3}{|l|}{ TNM stage } \\
\hline I & 584 & 32.8 \\
\hline II & 483 & 27.1 \\
\hline III & 349 & 19.6 \\
\hline IV & 365 & 20.5 \\
\hline
\end{tabular}

Table 1 (continued)
Table 1 (continued)

\begin{tabular}{lcc}
\hline Variables & Number & $\%$ \\
\hline Tumor size & & \\
Less than $4 \mathrm{~cm}$ & 697 & 39.1 \\
Greater than $4 \mathrm{~cm}$ & 514 & 28.9 \\
Unknown & 570 & 32.0 \\
Surgery & & \\
Yes & 634 & 35.6 \\
No & 1,133 & 63.6 \\
Unknown & 14 & 0.8 \\
Radiation & & \\
Yes & 1,332 & 74.8 \\
No & 449 & 25.2 \\
\hline
\end{tabular}

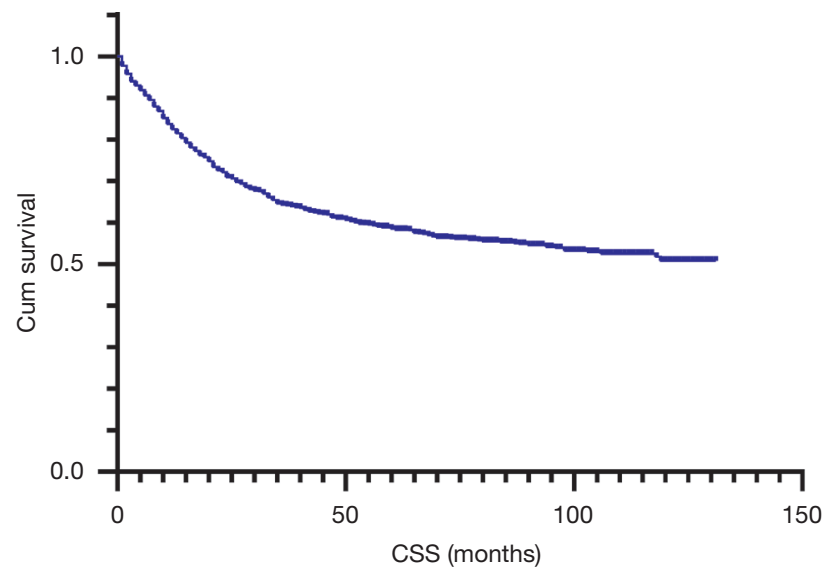

Figure 1 Survival curves for 1,781 patients with PVC (CSS is abbreviation for cause-specific survival).

reports. The majority of vaginal cancer is stage $\mathrm{I}$ as has been previously described (5). It was also found in our study that $32.8 \%$ of patients were stage I, occupying the largest proportion.

Reports of 5-year survival rates for PVC vary from $24 \%$ to $77.3 \%(14,22,23)$. Prognosis correlates strongly with disease stage. Five-year survival in larger series range from $64 \%$ to $84 \%$ for stage I, $53-75 \%$ for stage II, $36-46 \%$ for stage III and $3-36 \%$ for stage IV $(9,24,25)$. In our study, 5-year CSS for all patients was $57.8 \%$, and $76.4 \%$ (stage I), 61.9\% (stage II), 53.3\% (stage III) and $22.5 \%$ (stage IV). Major predictors of clinical outcome could be 
A

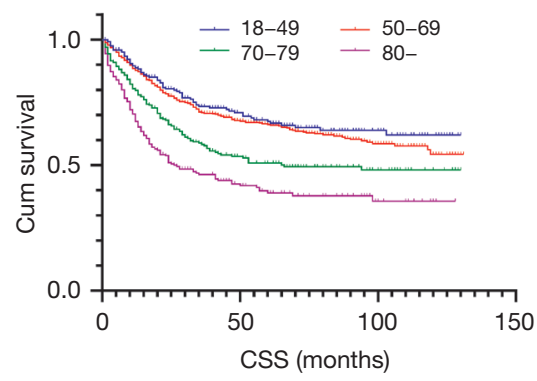

D

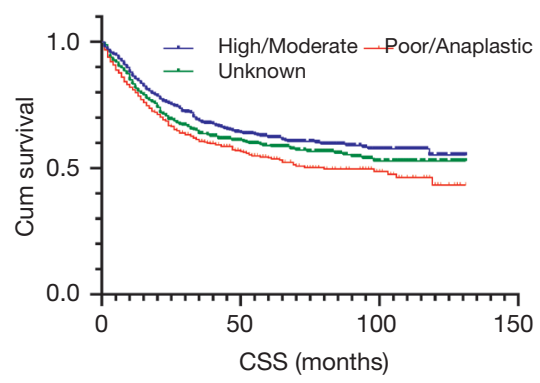

G

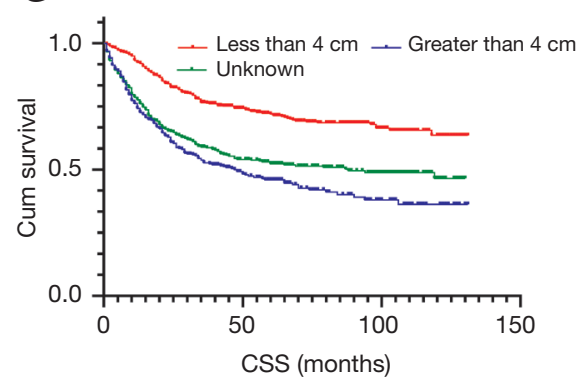

B

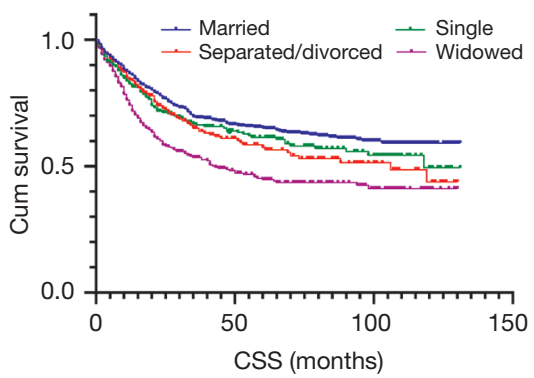

E

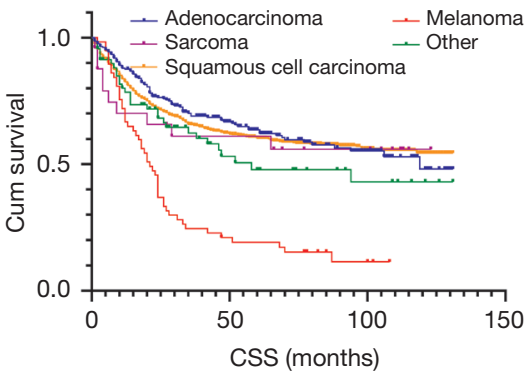

$\mathrm{H}$

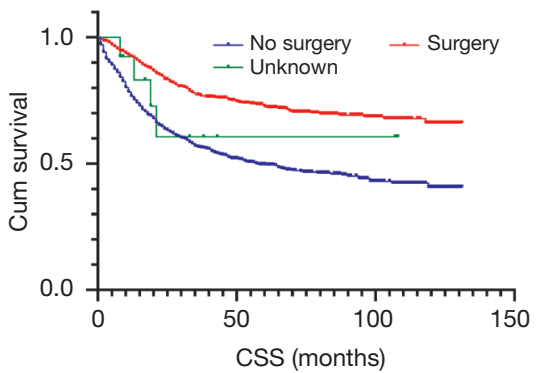

C

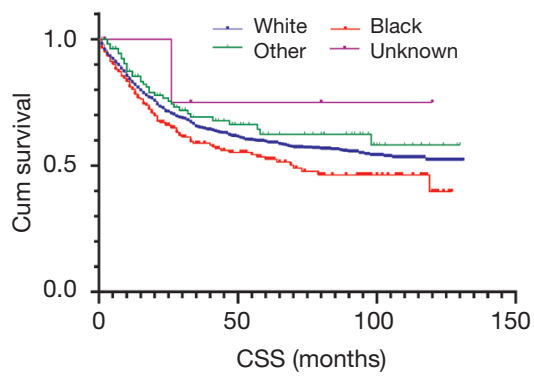

$\mathrm{F}$

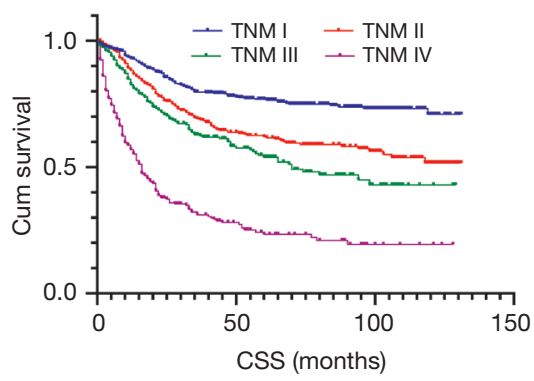

I

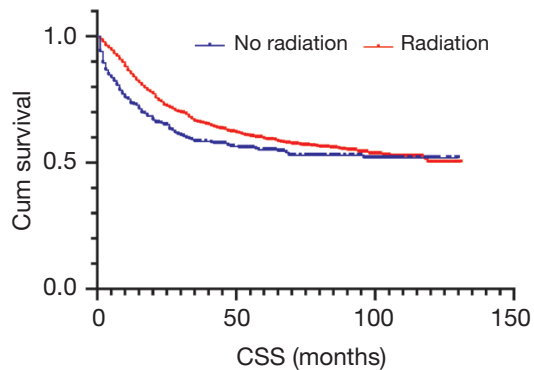

Figure 2 Survival curves for patients with PVC in univariate analysis. Survival curves (A,B,C,D,E,F,G,H,I) represent age, marital status, race, pathological grading, histology, TNM stage, tumor size, surgery and radiation, respectively $(\mathrm{P}<0.05)$.

grouped as patients' factors (performance status, older age, tobacco use, comorbidities, HPV-status, race, status of uterus) $(5,11,12,23,26-29)$; tumor factors (disease stage, tumor size, histological type, pelvic lymph node metastasis, tumor site, grade of differentiation) $(5,12,14,23,26,27)$; and treatment parameters (lymphadenectomy, brachytherapy utilization, concurrent chemoradiotherapy, higher facility volume, surgery, radiation dose, chemotherapy status) $(11,14,15,25,29,30)$. Based on our univariate analysis results, age, marital status, race, pathological grade, histology, TNM stage, tumor size, surgery and radiation were related to prognosis. Multivariate analysis suggested that age, histology, TNM stage, tumor size, surgery and radiation were independent prognostic factors.

Notably, our study confirms the results of various prior reports that have evaluated prognostic factors for PVC, lending credence to our findings. Stage is recognized as the most important determinant of prognosis for patients with PVC $(9,11,12,14,23,27)$. Higher stage may be associated with more comorbidities, or decreased odds of surgery or lower radiation dose, and would therefore lead to poorer survival. Hiniker et al. reported that stage was the single best indicator of prognosis (31). A recent study showed that not only overall survival (OS), but also disease-free survival (DFS) and CSS for each stage of PVC were significant correlated with stage (12). In our study, compared with women with stage I disease, patients with stage II, stage III and stage IV disease had elevated mortality risks (HR: $1.77,2.28$ and 5.43, respectively). Marital status is reported to be an independent prognostic factor for survival for 
Table 2 Univariate and multivariate survival analyses

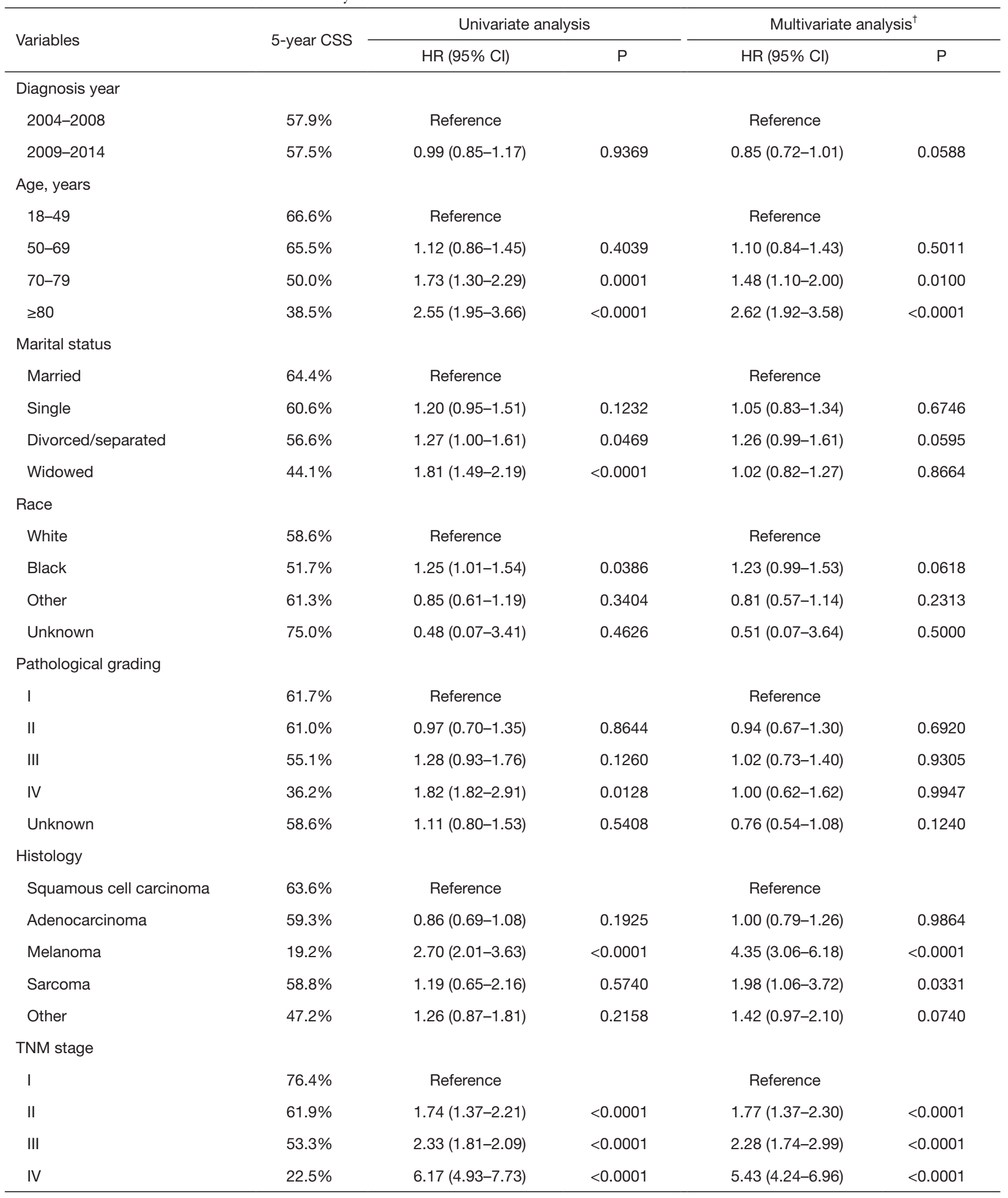

Table 2 (continued) 
Table 2 (continued)

\begin{tabular}{|c|c|c|c|c|c|}
\hline Variables & 5-year CSS & \multicolumn{2}{|c|}{ Univariate analysis } & \multicolumn{2}{|c|}{ Multivariate analysis $^{\dagger}$} \\
\hline \multicolumn{6}{|l|}{ Tumor size } \\
\hline Less than $4 \mathrm{~cm}$ & $71.8 \%$ & Reference & & Reference & \\
\hline Greater than $4 \mathrm{~cm}$ & $45.4 \%$ & $2.49(2.04-3.04)$ & $<0.0001$ & $1.62(1.31-2.01)$ & $<0.0001$ \\
\hline \multicolumn{6}{|l|}{ Surgery } \\
\hline No & $48.9 \%$ & Reference & & Reference & \\
\hline Yes & $72.1 \%$ & $0.43(0.36-0.51)$ & $<0.0001$ & $0.46(0.38-0.57)$ & $<0.0001$ \\
\hline Unknown & $60.6 \%$ & $0.67(0.25-1.80)$ & 0.4296 & $0.66(0.24-1.79)$ & 0.4132 \\
\hline Yes & $59.4 \%$ & $0.69(0.58-0.82)$ & $<0.0001$ & $0.52(0.43-0.63)$ & $<0.0001$ \\
\hline
\end{tabular}

Table 3 Univariate and multivariate analyses of survival by age, histology, and cancer stage

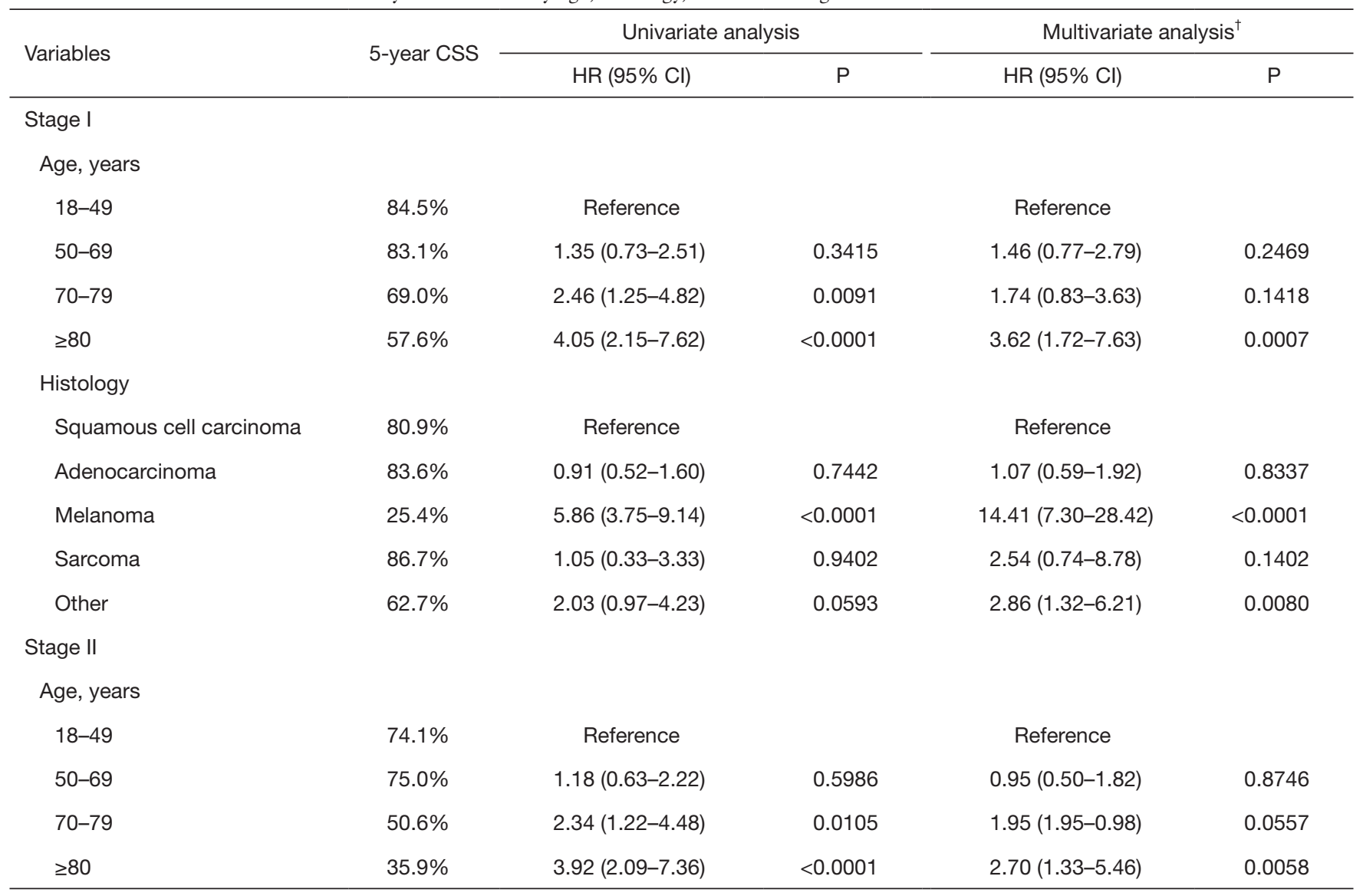

Table 3 (continued) 
Table 3 (continued)

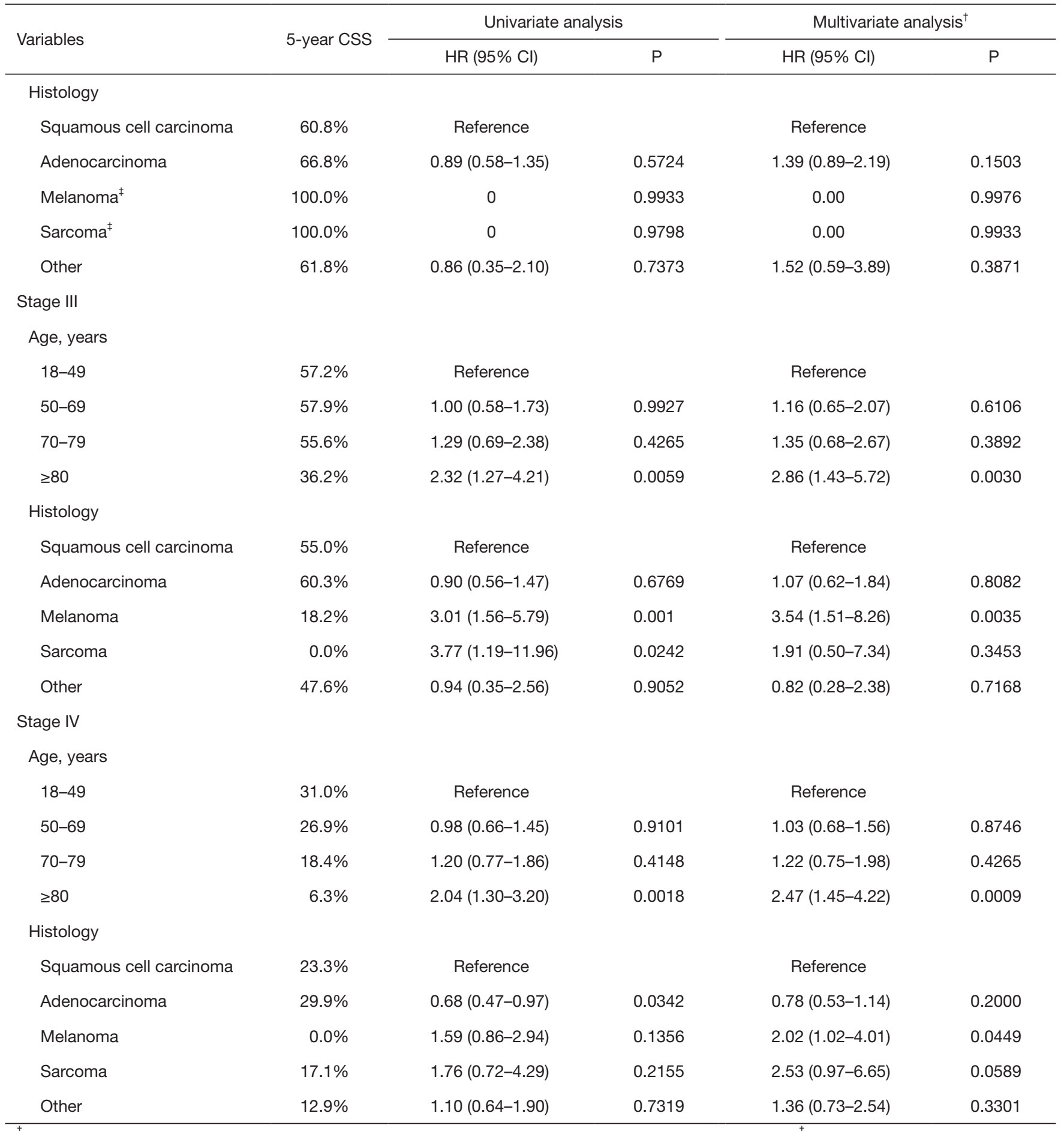

${ }^{\dagger}$, model adjusted for year of diagnosis, marital status, race, tumor size, grade, surgery, and radiation; ${ }^{\ddagger}$, this cohort included 1 stage II melanoma case and 1 stage II sarcoma case; both of these patients were still alive at last follow-up. 
various gynecologic cancers, including vulvar, cervical, uterine and ovarian cancers, with married women enjoying longer survival and lower mortality (16-19). The stress and loss of social support that may accompany the loss of a spouse, or lack of social support for widowed, single or divorced women seems very apparent, and may alter immune function and contribute to tumor progression and mortality (32). Marriage status may receive more psychosocial support than widowed status through the psychoimmunological pathway. Wu et al. showed that being widowed was associated with greater risk of vulvar cancer mortality than that of nonwidowed counterparts (16). Machida $e t$ al. indicated that single marital status was significantly associated with increased cumulative risk of all-cause mortality and infectious mortality compared with the married status in cervical cancer (17). In an analysis of epithelial ovarian cancer from 1988 to 2006, Mahdi et al. found that women who were unmarried (single, widowed and divorced) had more advanced stage and higher allcause mortality than married women (18). Lowery, et al. in their study of uterine cancer from 1991 to 2010, showed that compared with married, single, and divorced status, widowed status was an independently significant adverse factor (19). In our univariate analysis, the 5-year CSS of married women is $64.4 \%$, while those of divorced/separated and widowed are $56.6 \%$ and $44.1 \%$, respectively (divorced/ separated vs. married: HR 1.27, $\mathrm{P}=0.0469$; widowed $v s$. married: HR 1.81, $\mathrm{P}<0.0001)$. Widowed and divorced/ separated women are probably less likely to be in a sexual relationship that may delay the diagnosis of vaginal cancer, while postcoital bleeding is a typical early symptom. Also being widowed and divorced/separated may lead to heighten emotional stress that can stimulate sympathetic responses and impair immune response. To our knowledge, this is the first study to show that the widowed and divorced/separated patients with PVC have lower survival and greater risk of death than married patients. Although multivariate analysis does not show any significant finding, further studies are needed.

Larger primary tumor size was associated with higher incidence of local failure, thereby negatively affecting survival. In a multivariate analysis of PVC patients, Hellman et al. (33) reported that lesions larger than $4 \mathrm{~cm}$ is a poor prognostic factor (HR: 2.1). Similar results were also obtained by Wolfson et al. (13), although the cutoff was changed to $2 \mathrm{~cm}$; they reported that 5 -year OS in patients with tumors sized $\leq 2 v s .>2 \mathrm{~cm}$ were $79.2 \% v s$. $66.1 \%$ in stage $\mathrm{I}(\mathrm{P}=0.0187)$ and $80.9 \%$ vs. $51.2 \%$ in stage
II $(\mathrm{P}=0.0369)$. We got similar results when the cut-off was $5 \mathrm{~cm}$, which is consistent with Lian et al. (14). Similarly, in our study, tumor size $>4 \mathrm{~cm}$ was associated with a 1.62 -fold increase of mortality risk in multivariate analysis.

Currently, no consensus on standardized treatment for PVC is available. As vaginal cancer partially contains the same epithelium as cervical cancer, and they share many of the same exposures and risk factors, PVC has often been treated similarly to cervical cancer. In principle, the mainstay therapy for vaginal cancer is radiation therapy $(9,15)$. However, surgery is also an option. If diagnosed and staged earlier, both surgical resection and radiation can be curative in vaginal cancer $(9,10)$. In the case of a stage I or II tumor in the upper vagina, radical or modified radical hysterectomy and pelvic lymphadenectomy are often selected, in combination with vaginectomy with sufficient margin (10). And it was reported that the prognosis was better for surgical therapy than for radiation therapy alone if the tumor was located in the upper one-third of the vagina in clinical stage I or II $(22,34)$. For adenocarcinoma, which is usually resistant to radiotherapy, surgical treatment has been recommended (35). However, for most patients, especially with advanced disease and unresectable tumors, radiation plays a central role in PVC treatment $(9,15)$. Our data suggest decreased mortality rates in women who undergo surgery or radiation (HR: 0.46 or 0.52 , respectively).

Vaginal cancer is primarily a disease of elderly women. Camille et al. (27) indicated that age $>60$ years was negatively associated with survival $(\mathrm{P}=0.0339$; HR: 2.162). Wu et al. (7) also found that 5-year relative survival rates were lower among older women than among younger women with the same disease stage, and 5 -year relative survivals for all stages combined were $80.9 \%, 73.9 \%$ and $49.5 \%$ for years $<50,50-64$ and $>65$, respectively. However, Prameela et al. (12) reported no significant difference in OS, DFS or CSS between younger and older age groups. Platta et al. (36) had also failed to document any impact for age on treatment results. In our study, multivariate analysis indicated that age was an independent prognostic factor. Compared with women aged 18-49 years, women aged $70-79$ years and those aged $\geq 80$ years had higher mortality risks (HR: 1.48 and 2.62, respectively). A stratified analysis of the effect of age on survival by disease stage showed that, although women aged $\geq 80$ years had higher mortality risk than women aged 18-49 years, the difference in mortality risk by age tended to decrease as disease stage progressed. Age has a greater impact on survival in patients with 
earlier-stage disease. Interestingly, 80 years seems to be an important age cut point. Ghia et al. (23) reported that age older than 80 years (HR: 1.78; $\mathrm{P}=0.04$ ) was associated with worse OS in a retrospective analysis. This may be related to the high comorbidity and limited treatment among older women.

Several studies have shown SCC tumors in PVC to have a survival advantage (11), whereas melanomas have a poor prognosis $(5,25)$. Although most literature reports 5 -year OS for vaginal melanoma to be less than $20 \%(5,6)$, Chirag et al. reported it to be $70 \%$ (which is much higher than that in other studies), and that patients with vaginal melanoma had a 1.51 -fold increased mortality risk compared with vaginal SCC (25). In our study, 5-year CSS rates were $63.6 \%$ and $19.2 \%$ for women with SCC and melanoma, respectively, with a relatively higher mortality risk for women with melanoma (HR: 4.35). A stratified analysis of the effect of histology on survival by disease stage showed that, although melanoma carried a higher mortality risk than did SCC, this effect tended to decline as tumor stage progressed. Histology type seems to have a greater impact on survival in earlier-stage disease. The poor prognosis has been attributed to a variety of factors, including the poor visibility of vaginal melanoma (especially from the relatively high rate of amelanotic tumors), and anatomical proximity to the vulvovaginal venous plexus, leading to difficulties in surgery and radiotherapy; these factors are more pronounced in advanced patients.

\section{Conclusions}

In conclusion, PVC is a rare gynecological malignant tumor and more likely to occur among older women. SCC is the most histological type of PVC, whereas melanoma is extremely rare. Age, histology, TNM stage, tumor size, surgery and radiation are independent prognostic factors. Married individuals seem to enjoy longer survival and lower mortality compared with widowed and divorced/separated women. Age $\geq 80$ years seems to be an important cut point in the survival of vaginal cancer. The elderly $(\geq 80)$ cases and those with melanoma were correlated to worse prognosis at any stage of PVC. Age $\geq 80$ years and melanoma seem to have greater influences on mortality risk in patients with early-stage disease. However, we must acknowledge its limitations in our study. First, its retrospective design is a potential source of bias. Second, several covariates of interest are unavailable from the SEER database, including HPV, smoking, number of lifetime partners, radiotherapy dose, surgical details, and data on chemotherapy, which have been associated with PVC incidence and survival. Therefore, large-scale, prospective studies are urgently needed.

\section{Acknowledgments}

The authors acknowledge the efforts of the Surveillance, Epidemiology, and End Results (SEER) Program tumor registries in the creation of the SEER database. The interpretation and reporting of these data are the sole responsibility of the authors.

Funding: None.

\section{Footnote}

Reporting Checklist: The authors have completed the STROBE reporting checklist. Available at http://dx.doi. org/10.21037/tcr-20-1825

Peer Review File: Available at http://dx.doi.org/10.21037/tcr20-1825

Conflicts of Interest: All authors have completed the ICMJE uniform disclosure form (available at http://dx.doi. org/10.21037/tcr-20-1825). The authors have no conflicts of interest to declare.

Ethical Statement: The authors are accountable for all aspects of the work in ensuring that questions related to the accuracy or integrity of any part of the work are appropriately investigated and resolved. The data had been authorized by SEER database and ethical review was not required. The study was conducted in accordance with the Declaration of Helsinki (as revised in 2013).

Open Access Statement: This is an Open Access article distributed in accordance with the Creative Commons Attribution-NonCommercial-NoDerivs 4.0 International License (CC BY-NC-ND 4.0), which permits the noncommercial replication and distribution of the article with the strict proviso that no changes or edits are made and the original work is properly cited (including links to both the formal publication through the relevant DOI and the license). See: https://creativecommons.org/licenses/by-nc-nd/4.0/.

\section{References}

1. Damast S, Takiar V, McCarthy S, et al. Treatment of 
early stage vaginal cancer with EBRT and MRI-based intracavitary brachytherapy: A retrospective case review. Gynecol Oncol Rep 2016;17:89-92.

2. Siegel RL, Miller KD, Jemal A. Cancer statistics, 2016. CA Cancer J Clin 2016;66:7-30.

3. Siegel RL, Miller KD, Jemal A. Cancer Statistics, 2017. CA Cancer J Clin 2017;67:7-30.

4. Madsen BS, Jensen HL, van den Brule AJ, et al. Risk factors for invasive squamous cell carcinoma of the vulva and vagina-Population-based case-control study in Denmark. Int J Cancer 2008;122:2827-34.

5. William T C, Phillips JL, Menck HR. The National Cancer Data Base Report on Cancer of the Vagina. American Cancer Society 1998;83:1033-40.

6. Tasaka R, Fukuda T, Wada T, et al. A retrospective clinical analysis of 5 cases of vaginal melanoma. Mol Clin Oncol 2017;6:373-6.

7. Wu X, Matanoski G, Chen VW, et al. Descriptive epidemiology of vaginal cancer incidence and survival by race, ethnicity, and age in the United States. Cancer 2008;113:2873-82.

8. Akino N, Wada-Hiraike O, Matsumoto Y, et al. Vaginal cancer possibly caused by pessary and immunocompromised condition: Multiple risk factors may influence vaginal cancer development. J Obstet Gynaecol Res 2016;42:748-51.

9. Frank SJ, Jhingran A, Levenback C, et al. Definitive radiation therapy for squamous cell carcinoma of the vagina. Int J Radiat Oncol Biol Phys 2005;62:138-47.

10. Saito T, Tabata T, Ikushima H, et al. Japan Society of Gynecologic Oncology guidelines 2015 for the treatment of vulvar cancer and vaginal cancer. Int J Clin Oncol 2018;23:201-34.

11. Rajagopalan MS, Xu KM, Lin JF, et al. Adoption and impact of concurrent chemoradiation therapy for vaginal cancer: a National Cancer Data Base (NCDB) study. Gynecol Oncol 2014;135:495-502.

12. Prameela CG, Ravind R, Gurram BC, et al. Prognostic Factors in Primary Vaginal Cancer: A Single Institute Experience and Review of Literature. J Obstet Gynaecol India 2016;66:363-71.

13. Wolfson AH, Reis IM, Portelance L, et al. Prognostic impact of clinical tumor size on overall survival for subclassifying stages I and II vaginal cancer: A SEER analysis. Gynecol Oncol 2016;141:255-9.

14. Lian J, Dundas G, Carlone M, et al. Twenty-year review of radiotherapy for vaginal cancer: an institutional experience. Gynecol Oncol 2008;111:298-306.
15. Yagi A, Ueda Y, Kakuda M, et al. Descriptive epidemiological study of vaginal cancer using data from the Osaka Japan population-based cancer registry: Long-term analysis from a clinical viewpoint. Medicine (Baltimore) 2017;96:e7751.

16. Wu SG, Lin QJ, Li FY, et al. Widowed status increases the risk of death in vulvar cancer. Future Oncol 2018;14:2589-98.

17. Machida H, Eckhardt SE, Castaneda AV, et al. Single Marital Status and Infectious Mortality in Women With Cervical Cancer in the United States. Int J Gynecol Cancer 2017;27:1737-46.

18. Mahdi H, Kumar S, Munkarah AR, et al. Prognostic impact of marital status on survival of women with epithelial ovarian cancer. Psychooncology 2013;22:83-8.

19. Lowery WJ, Stany MP, Phippen NT, et al. Survival advantage of marriage in uterine cancer patients contrasts poor outcome for widows: a Surveillance, Epidemiology and End Results study. Gynecol Oncol 2015;136:328-35.

20. Hellman K, Silfverswärd C, Nilsson B, et al. Primary carcinoma of the vagina: factors influencing the age at diagnosis. The Radiumhemmet series 1956-1996. Int J Gynecol Cancer 2004;14:491-501.

21. Joura EA, Leodolter S, Hernandez-Avila M, et al. Efficacy of a quadrivalent prophylactic human papillomavirus (types 6, 11, 16, and 18) L1 virus-like-particle vaccine against high-grade vulval and vaginal lesions: a combined analysis of three randomised clinical trials. Lancet 2007;369:1693-702.

22. Tjalma WA, Monaghan JM, de Barros Lopes A, et al. The role of surgery in invasive squamous carcinoma of the vagina. Gynecol Oncol 2001;81:360-5.

23. Ghia AJ, Gonzalez VJ, Tward JD, et al. Primary vaginal cancer and chemoradiotherapy: a patterns-of-care analysis. Int J Gynecol Cancer 2011;21:378-84.

24. de Crevoisier R, Sanfilippo N, Gerbaulet A, et al. Exclusive radiotherapy for primary squamous cell carcinoma of the vagina. Radiother Oncol 2007;85:362-70.

25. Shah CA, Goff BA, Lowe K, et al. Factors affecting risk of mortality in women with vaginal cancer. Obstet Gynecol 2009;113:1038-45.

26. Ikushima H, Wakatsuki M, Ariga T, et al. Radiotherapy for vaginal cancer: a multi-institutional survey study of the Japanese Radiation Oncology Study Group. Int J Clin Oncol 2018;23:314-20.

27. Gunderson CC, Nugent EK, Yunker AC, et al. Vaginal cancer: the experience from 2 large academic centers during a 15 -year period. J Low Genit Tract Dis 
2013;17:409-13.

28. Larsson GL, Helenius G, Andersson S, et al. Prognostic impact of human papilloma virus (HPV) genotyping and HPV-16 subtyping in vaginal carcinoma. Gynecol Oncol 2013;129:406-11.

29. Mahdi H, Kumar S, Hanna RK, et al. Disparities in treatment and survival between African American and White women with vaginal cancer. Gynecol Oncol 2011;122:38-41.

30. Miyamoto DT, Viswanathan AN. Concurrent chemoradiation for vaginal cancer. PLoS One 2013;8:e65048.

31. Hiniker SM, Roux A, Murphy JD, et al. Primary squamous cell carcinoma of the vagina: prognostic factors, treatment patterns, and outcomes. Gynecol Oncol 2013;131:380-5.
32. Antoni MH, Lutgendorf SK, Cole SW, et al. The influence of bio-behavioural factors on tumour biology: pathways and mechanisms. Nat Rev Cancer 2006;6:240-8.

33. Hellman K, Lundell M, Silfverswärd C, et al. Clinical and histopathologic factors related to prognosis in primary squamous cell carcinoma of the vagina. Int J Gynecol Cancer 2006;16:1201-11.

34. Tabata T, Takeshima N, Nishida H, et al. Treatment failure in vaginal cancer. Gynecol Oncol 2002;84:309-14.

35. Adams TS, Cuello MA. Cancer of the vagina. Int J Gynaecol Obstet 2018;143 Suppl 2:14-21.

36. Platta CS, Anderson B, Geye H, et al. Adjuvant and definitive radiation therapy for primary carcinoma of the vagina using brachytherapy and external beam radiation therapy. J Contemp Brachytherapy 2013;5:76-82 .
Cite this article as: Huang J, Cai M, Zhu Z. Survival and prognostic factors in primary vaginal cancer: an analysis of 2004-2014 SEER data. Transl Cancer Res 2020;9(11):7091-7102. doi: $10.21037 /$ tcr-20-1825 